\title{
RESEÑA: EJEMPLOS DE MALTRATO AL FEMINISMO EN LA ZARZUELA. FRANCISCO ROSAL NADALES ${ }^{1}$
}

\author{
María José Ramos Rovi
}

\author{
Francisco Rosal Nadales, Ejemplos de Maltrato al feminismo en la Zarzuela \\ (1876-1908). Almería: Diputación de Almería y Delegación de igualdad, 2015. \\ ISBN: 9788481086041
}

La presente obra suple, en parte, una de las carencias existentes en la historiografía contemporánea española: la inexistencia de un estudio con perspectiva de género de los libretos de la zarzuela. Con el seudónimo de "safo Pardo Bazán”, el profesor Rosal se presentó al premio de ensayo "Carmen de Burgos" en el año 2014. Este certamen es convocado anualmente por la Diputación Provincial de Almería. En las bases de la convocatoria de este premio aparece que, se valorarán trabajos de gran calidad literaria, realizados con perspectiva feminista y, por supuesto, obras de gran originalidad. Todos estos requisitos se cumplen en la monografía presentada por Francisco Rosal. La originalidad comienza en el alias: "safo Pardo Bazán". Safo es un personaje que aparece en el libreto El trust de las mujeres. Éste es un nombre griego escogido con una doble intencionalidad: por un lado literario, la mujer escribe poesía y por otro histórico, pues promueve un arte poético en grupos formados exclusivamente por mujeres. En el libreto analizado Safo es directora de un semanario feminista en el que intenta emular a los grandes poetas españoles. Y, qué decir de doña Emilia Pardo Bazán “condesa de Pardo Bazán” una de nuestras grandes escritoras contemporáneas.

\footnotetext{
${ }^{1}$ Fecha de recepción: 29/08/2016.

Fecha de aceptación: 30/08/2016.

2 Profesora Contratada Doctora, Departamento de Historia Moderna, Contemporánea y de América, Universidad de Córdoba; $₫$ hi1rarom@uco.es.
} 
Como nos indica el autor en la introducción de su libro a través del análisis de varios libretos de zarzuela, nos quiere trasladar qué visión de la mujer, de su ansia de equiparación y de su afán de crear asociaciones para igualarse a los hombres o emanciparse, se dio en ese mundo del teatro lírico que tanta presencia tuvo en la cultura española entre 1876 y 1908. Para ello, el profesor Nadal ha analizado siete libretos de la época. El primero Una aventura en Siam (Madrid, 1876) que consta de dos actos. El primero es un arreglo realizado por Javier de Burgos de una pieza francesa anterior y el segundo es original de Calixto Navarro. La música se debió a Isidoro Hernández. El segundo de los libretos analizados La mano blanca (Madrid, 1884) fue escrito por José Jackson Veyán y la música era de los maestros Ángel Rubio y Casimiro Espino. Con el llamativo sobrenombre de "despropósito trágico-lírico", se estreno en enero de 1887 en el Teatro de la Princesa la obra Las mujeres que matan. El libreto era de Carlos Coello Pacheco y la música del maestro Manuel Fernández Caballero. El 5 de mayo de 1888 se estrenó en el Teatro Apolo el libreto de Salvador Ma Granés, La liga de las mujeres. Este escritor era un experto en parodiar obras teatrales y óperas de éxito, mientras que la música era de Guillermo Cereceda. Otra de las obras estudiadas es una "fantasía cómicolirica" con el título Congreso Feminista estrenada en 1904. El libreto salió de las plumas de Celso Lucio, Enrique García Álvarez y Manuel Fernández Palomero y la música fue escrita por Quinito Valverde. Por su parte, los libretistas Ramón Asensio Mas y Gerónimo Giménez escribieron El trust de las mujeres (Madrid, 1908), otra humorada a costa de las mujeres y de la lucha por destacar en cualquier oficio. Manuel Fernández de la Puente y Luis Pascual escribieron el libreto Si las mujeres mandases, (Madrid, 1908) que, como dice el autor "nuevamente estamos ante una obra con la que se pretende ofrecer situaciones cómica a costa de los derechos de las mujeres y mostrar el máximo de anatomía femenina".

Cada uno de estos títulos encabeza los capítulos en los que se articula el libro. Estos libretos del llamado "género chico" tienen en común que en sus argumentos no se consiente y se ridiculiza cualquier pretensión de la mujer de ocupar puestos políticos y administrativos, o su afán por recibir una completa preparación. Estos autores no eran ajenos al sentir de la época. Por aquellos años, los hermanos Álvarez Quintero publicaron 
el libro titulado Ruido de faldas. Entremeses y pasos escogidos, con un prólogo sobre feminismo, (Madrid, 1917). En ese prólogo manifestaban su rechazo al feminismo: "No somos partidarios del feminismo, Lo consideramos hasta contrario a la naturaleza. El empleo de la mujer en la vida lo ha legislado Dios, haciéndola diferente del hombre, a quien se la dio por compañera”. Este comentario nos indica el sentir de la época.

A lo largo de los capítulos de esta obra, Francisco Rosal analiza con detalle el tratamiento de los libretistas sobre distintos oficios y se pregunta ¿decidirían ridiculizar sin piedad a aquellas mujeres que osaban equipararse a los hombres? O, tal vez, no eran conscientes de esa discriminación. Por ejemplo, en el capítulo "Una aventura en Siam" se analiza esta zarzuela donde aparecen "militaras". Nos dice el autor que, en esta zarzuela no aparece recogida ninguna reivindicación femenina. Simplemente es un divertimento del público masculino al contemplar a las mujeres en ropas y tareas no femeninas por tradición: "el batallón de mujeres no es una conquista social sino un recurso para el deleite visual y psicológico de los espectadores masculinos".

En aquellos momentos históricos, la mayoría de las españolas vivían la desigualdad como algo natural. En estas zarzuelas y la mentalidad imperante, el hombre siempre triunfa sobre la mujer. Este es el argumento de dos de los libretos de las zarzuelas analizados. Las mujeres que matan, estrenada en 1887 y la obra La liga de las mujeres interpretada un año después.

En 1896 se celebró en París el V Congreso Feminista Internacional y, en junio de 1904, tuvo lugar un Congreso Internacional Femenino, en Berlín. La celebración de estos eventos inspiró a la zarzuela titulada Congreso Feminista, estrenado en el Teatro Moderno, en marzo de 1904. Según el libreto, las mujeres entre sus reclamaciones incluyen el poder piropear a los hombres y, claro está, esto sirve para desarmar el carácter reivindicativo. Por otro lado, destacar que en esta obra aparecen futbolistas, con la única intención de lucir el cuerpo femenino para el deleite de la vista masculina. Esa muestra del cuerpo femenino se aprecia en el último de los libretos analizados Si las mujeres mandasen. A lo largo de sus páginas, nuevamente estamos ante una obra con la que se 
pretende ofrecer situaciones cómicas a costa de los derechos de las mujeres y mostrar el máximo de anatomía femenina.

Como el autor nos relata, la zarzuela es muy permeable a las noticias y en el escenario muestra su peculiar visión de la realidad. No olvidemos que lo que pretende es dar un espectáculo, divertir al público y ganar dinero. Las reivindicaciones femeninas son uno más de esos argumentos utilizados. El problema surge cuando se emplea exclusivamente para hacer reír al público y se maltrata a las mujeres en las letras de los libretos. En conclusión, Ejemplos de (Mal)traro al feminismo en la Zarzuela (1876-1908) de Francisco J. Rosal Nadales es un trabajo de un gran rigor científico, que nos acerca a la España contemporánea. 